\title{
Parametric method for determination of motion characteristics of underwater vehicles, applicable in preliminary designing
}

\author{
Jan P. Michalski, Assoc. Prof. \\ Gdańsk University of Technology \\ Polish Naval University
}

ABSTRACT

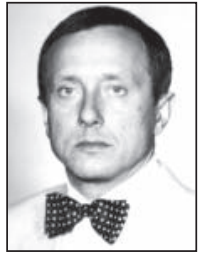

This paper describes a method for preliminary designing the autonomous underwater vehicles (AUV), especially useful in the case when requirements concerning kinematic and dynamic parameters of vehicle motion are given in design assumptions. Concept of the method is based on dynamic equations which describe vehicle planar motion in vertical and horizontal directions, resulting from action of screw propellers or water ballast, respectively. The motion equations were determined by applying simplifications concerning both geometrical description of vehicle's form and flow phenomena. Their solutions were obtained in the form of closed analytical expressions which are both of cognitive and practical merits as they can serve to assess influence of vehicle's design parameters on its motion characteristics and simultaneously are convenient to formulate design optimization problems. Application of the method was illustrated by the attached examples dealing with determination of kinematic and dynamic characteristics of motion of the vehicle „Scylla” of set geometrical configuration and propulsion parameters.

Keywords: underwater vehicles; preliminary designing method

\section{INTRODUCTION}

Underwater vehicles serve to carry out scientific research; they find applications in offshore industry and to military important purposes. Variety of their operational applications is associated with a wide range of functional demands including those regarding movement properties. Selection of both geometrical configuration of a vehicle and its propulsion system greatly depends on demands put to its motion. The presented method is intended for preliminary approximate prediction of kinematic and dynamic properties of motion of autonomous underwater vehicles on the basis of set of technical parameters which identify designed vehicle already in early design stages. Research on underwater vehicles belongs to the area of interest of many research centers all over the world. This can be exemplified by multi-year commitment of Massachusetts Institute of Technology to realization of comprehensive research carried out in the frame of Sea Grant project, or that realized by Virginia Polytechnic Institute and State University, as well as by many other scientific institutions whose list can be found in [1].

In state of immersion, the remotely operated vehicle ( $R O V)$, or also autonomous underwater vehicle $(A U V)$ can perform motion of six degrees of freedom, like airplane in flight. Differential equations which describe such motion - due to large number of independent variables, their high order, non-linearity and coupling as well as due to complex boundary conditions - constitute a difficult mathematical problem [2, 3, 4], applied in the stage of design verification calculations. In the practical preliminary designing of underwater vehicles of complex forms resulting from their functions it is necessary to make preliminarily use of parametric design methods based on such mathematical models, that leads - at allowable simplifications - to efficient determination of acceptable approximate solutions.

When operation of an underwater vehicle consists mainly in moving with constant speed as in the case of classical transport ships then the designing of its hull form and propulsion system is based on hull steady-motion resistance characteristics. However if its operation is inherently associated with frequent changes of motion speed in order to realize vehicle's functions (underwater operations and working tasks) then to use dynamic resistance-propulsion characteristics in unsteady motion is necessary in its designing, that constitutes a non-classical task of ship design theory.

The problem presented in this paper concerns elaboration of a method applicable to the designing of underwater vehicles in the case when design assumptions contain requirements dealing with kinematic and dynamic parameters of designed vehicle, e.g. such as the following:

is to cover a given distance within a set time

$i$ to develop a required speed within a set time

$i$ to develop a required speed along a set distance.

Concept of the method is based on selection of a form of planar motion equation for a vehicle which moves in two 
orthogonal directions: horizontal or vertical. Usefulness of the method for engineering applications can be assessed by examining fulfillment of the following criteria:

* to be capable of predicting the kinematic and dynamic characteristics of underwater vehicles

* to be applicable to preliminary designing the underwater vehicles identified by a scarce set of numerical design parameters

* to be applicable to realizing research tasks intended for gaining knowledge on ranges of permissible values of design parameters of underwater vehicles, and to have practical application merits.

Vehicle motion is forced by thrust force generated by screw propellers, or by resultant of vehicle buoyancy force and its weight dependent on a chosen amount of water ballast. Application of the method is illustrated by the attached examples which concern assessment of influence of values of design parameters of geometrical configuration as well as propulsion system's parameters of a vehicle on its motion characteristics.

\section{INVESTIGATION METHOD AND AIM OF THE WORK}

The applied investigation method consists in formulation of equations of underwater vehicle motion, expressed by means of its main design parameters, determination of their analytical solutions, as well as elaboration of computational algorithms in order to perform test calculations. Mathematical model of vehicle motion was elaborated by assuming simplifications which concerned both vehicle geometrical form description and flow phenomena. Expressions describing relations between object's geometrical parameters and forces exerted onto vehicle, were determined on the basis of theoretical knowledge as well as results of experimental investigations, taken from the subject-matter literature sources [5, 6].

Motion equations in their initial form express equilibrium of forces acting onto vehicle, i.e. inertia forces of vehicle mass inclusive of added water mass, thrust of propellers, vehicle resistance, its weight and buoyancy. Values of the forces depend on vehicle parameters, water environment features, values of vehicle speed and acceleration. So determined dynamic characteristics of motion are functions dependent on time, displacement, speed, acceleration and design parameters of vehicle.

Their solutions determined in the form of close analytical relations, have both cognitive and practical merits as they make it possible to investigate in a simple and straight way influence of vehicle design parameters on its motion characteristics; moreover they are convenient for formulation of design optimization problems useful to computer aided preliminary designing. Summing up, the aim of the work in question consists in elaboration of a practical engineering method applicable to the preliminary designing of autonomous underwater vehicles of given set motion parameters - performed by means of analytically expressed vehicle motion characteristics. Simplifications of the method, based on engineering practice, concern geometrical form description, choice of directions of vehicle motion, omittment of less important forces; and, they particularly concern the following:

O unsteady rectilinear motion described by non-linear differential equations

$\rightarrow$ application of hypothesis on invariability of vortex forces in steady and unsteady motions

$\rightarrow$ omittment of action of lift forces validity of the principle of superposition of forces

$\rightarrow$ constant values of physical parameters (water density and viscosity).

Vehicle's resistance depends on a kind of flow around its elements, which can be locally either laminar or turbulent, with or without separation of flow; the variety of flow kinds makes it difficult to provide unambiguous mathematical description of the phenomena on the ground of theoretical knowledge, that forces to introduce simplifying assumptions. Wave-generated resistance is negligible as operational range of vehicle is sufficiently far from water surface. Flow phenomena such as formation of boundary layer, viscosity resistance, pressure resistance, flow separation, generation of lift forces, or cavitation are analogous to those in the case of classical ships but they occur at different values of Reynold's number and pressure.

\section{MATHEMATICAL MODEL OF THE PROBLEM}

Vehicle's motion is described in the motionless rectangular coordinate system of z-axis pointing the gravity force direction, and horizontal x-axis, as shown in Fig. 1.

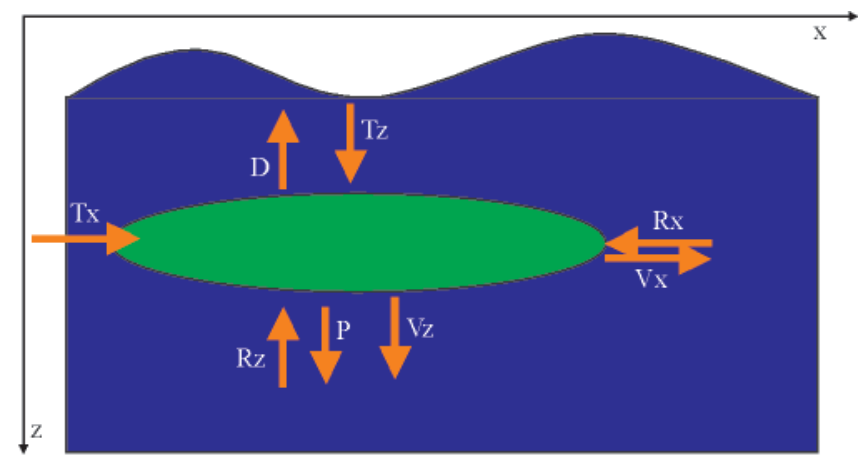

Fig. 1. The coordinates system and position of the vehicle respective to directions of its motion

The relationship of inertia force and external forces acting on vehicle of the component masses $\mathrm{M}_{\mathrm{j}}$, in unsteady rectilinear motion, is expressed as follows:

$$
\frac{\mathrm{ds}^{2-}}{\mathrm{dt}^{2}} \cdot \sum \mathrm{M}_{\mathrm{j}}=\sum \overline{\mathrm{F}}_{\mathrm{si}}
$$

If vehicle motion is directed along $\mathrm{z}$-axis then balance of forces is given by the equation:

$$
\begin{gathered}
\left(M_{p}+M_{b}\right) \cdot \frac{d^{2} z}{d t^{2}}= \\
=\left(M_{p}+M_{b}-D\right) \cdot g-R_{t z}\left(\frac{d z}{d t}\right)-B\left(\frac{d^{2} z}{d t^{2}}\right)
\end{gathered}
$$

where the following case is considered:

$$
\left(M_{p}+M_{b}-D\right) \cdot g=\left(M_{o}-\rho \cdot V\right) \cdot g=P-W \neq 0
$$

If vehicle motion is directed along $\mathrm{x}$-axis then balance of forces is given by the equation:

$$
\begin{gathered}
\left(M_{p}+M_{b}\right) \cdot \frac{d^{2} x}{{d t^{2}}^{2}}=\left(M_{p}+M_{b}-D\right) \cdot g+ \\
-R_{t x}\left(\frac{d x}{d t}\right)+T_{N}\left(\frac{d x}{d t}\right)-B\left(\frac{d^{2} x}{d t^{2}}\right)
\end{gathered}
$$


where the following case is considered:

$$
\left(M_{p}+M_{b}-D\right) \cdot g=\left(M_{o}-\rho \cdot V\right) \cdot g=P-W=0
$$

\section{SIMPLIFYING ASSUMPTIONS}

In the preliminary design stage, vehicle is identified by the vector of main design parameters, $\bar{x}$, and a set of attributes which describe geometrical configuration of vehicle form. Such identification is supplemented with a set of physical constants and data concerning characteristics of propellers and resistance characteristics of bodies of simple geometrical forms. It is assumed that at the considered vehicle motions the resistance and thrust forces are collinear, that is necessary to perform rectilinear motion.

Value of the force:

$$
\mathrm{B}\left(\frac{\mathrm{ds}^{2}}{\mathrm{dt}^{2}}\right)
$$

which accelerates mass of water surrounding the vehicle, has been replaced by value of the force which, to a determined mass of water, $\Delta \mathrm{M}_{\mathrm{s}}(\overline{\mathrm{x}})$, (the so-called added mass of water), gives acceleration equal to that of the vehicle itself:

$$
\mathrm{B}\left(\frac{\mathrm{d}^{2} \mathrm{~s}}{\mathrm{dt}^{2}}\right)=\Delta \mathrm{M}_{\mathrm{s}}(\overline{\mathrm{x}}) \cdot \frac{\mathrm{d}^{2} \mathrm{~s}}{\mathrm{dt}^{2}}
$$

Depending on the direction of vehicle motion, $\mathrm{s}=(\mathrm{x} \vee \mathrm{z})$, the mass $\Delta \mathrm{M}_{\mathrm{s}}$ takes the value proportional to the vehicle mass:

$$
\Delta \mathrm{M}_{\mathrm{s}}(\overline{\mathrm{x}})=\xi_{\mathrm{s}} \cdot \rho \cdot \mathrm{V}(\overline{\mathrm{x}})=\xi_{\mathrm{s}} \cdot \mathrm{D}(\overline{\mathrm{x}})
$$

The propelling force $T_{N}$ generated by $\mathrm{m}$ - propellers whose bollard thrust is equal to $\mathrm{T}_{\mathrm{N}}$, at variable velocity of water inflow to the propellers, can be approximated by the relationship:

$$
\begin{aligned}
& T_{N}(v, \bar{x})=m \cdot T_{o}(\bar{x}) \cdot\left(1-\frac{v \cdot(1-w)}{v_{k}}\right)= \\
& =m \cdot K_{T} \cdot \rho \cdot n_{p}^{24} \cdot D_{p} \cdot\left(1-\frac{v \cdot(1-w)}{v_{k}}\right)
\end{aligned}
$$

Is difficult to express vehicle resistance value by an analytical relation dependent on vehicle form because of its geometrical configuration which is complex, open-work and multiply-connected. Moreover, the difficulty results from the fact that object resistance values in steady and unsteady motion at the same speed are different, as indicated by results of experimental tests [7].

Simplification of the method concerning the determination of resistance, consists in assumption of hypothesis on invariability of vortex forces in steady and unsteady motions, that is justified in the case of flows without separation, i.e. occurring in the range of moderate values of Reynolds number and for streamline bodies. Ambiguouity with respect to a kind of flow around vehicle elements causes that for practical application of the method some calibration of the coefficients (or functions) $\mathrm{k}_{\mathrm{s}}$ as well as $\xi_{\mathrm{s}}$ is required.

The total vehicle resistance $\mathrm{R}_{\mathrm{s}}$ was expressed as the sum of the viscous resistance $R_{v}$ and the pressure resistance $R_{p}$ of vehicle elements, determined by using the formulae given in $[2,3]$, as well as ITTC-57 formula. The total vehicle resistance $\mathrm{R}_{\mathrm{s}}$ in motion in s-direction (along $\mathrm{x}$-axis or $\mathrm{z}$-axis) follows superposition without taking into account interferential influence of vehicle elements:

$$
\mathrm{R}_{\mathrm{s}}(\overline{\mathrm{x}})=\mathrm{R}_{\mathrm{v}, \mathrm{s}}(\overline{\mathrm{x}})+\mathrm{R}_{\mathrm{p}, \mathrm{s}}(\overline{\mathrm{x}})
$$

The viscosity resistance was expressed by the friction resistance $R_{f, s}$ and the form coefficients $k_{s}$, by summing the resistance values of particular vehicle elements of the reference surface areas $\Omega$ :

$$
\begin{aligned}
\mathrm{R}_{\mathrm{v}, \mathrm{s}}(\mathrm{v}, \overline{\mathrm{x}}) & =\frac{\rho \cdot \mathrm{v}^{2}}{2} \cdot \sum_{\mathrm{i}=1}^{\mathrm{n}}\left(1+\mathrm{k}_{\mathrm{s}_{\mathrm{i}}}\right) \cdot \mathrm{C}_{\mathrm{f}_{\mathrm{i}}, \mathrm{s}}(\overline{\mathrm{x}}) \cdot \Omega_{\mathrm{i}}(\overline{\mathrm{x}})= \\
& =\frac{\rho \cdot \mathrm{v}^{2}}{2} \cdot \sum_{\mathrm{i}=1}^{\mathrm{n}} \mathrm{C}_{\mathrm{v}_{\mathrm{i}}, \mathrm{s}}(\overline{\mathrm{x}}) \cdot \Omega_{\mathrm{i}}(\overline{\mathrm{x}})
\end{aligned}
$$

The friction resistance coefficient was determined by the ITTC-57 formula:

$$
\mathrm{C}_{\mathrm{f}_{\mathrm{i}}, \mathrm{s}}=\frac{0.075}{\left(\log \frac{\mathrm{v}_{\mathrm{s}} \cdot \mathrm{L}_{\mathrm{s}_{\mathrm{i}}}}{\mathrm{v}}-2\right)^{2}}=\frac{0.075}{\left(\log \frac{0.5 \cdot \mathrm{v}_{\mathrm{k}} \cdot \mathrm{L}_{\mathrm{s}_{\mathrm{i}}}}{\mathrm{v}}-2\right)^{2}}
$$

where the velocity $\mathrm{v}_{\mathrm{s}}$ was assumed equal to a half of zero-thrust velocity of propellers.

The pressure resistance coefficient concerning the slender elements of vehicle was determined in compliance with the formulae given in [3]:

$$
\mathrm{C}_{\mathrm{p}, \mathrm{s}}(\overline{\mathrm{x}})=\sum_{\mathrm{i}=1}^{\mathrm{n}}\left[\mathrm{C}_{\mathrm{v}_{\mathrm{i}}, \mathrm{s}}(\overline{\mathrm{x}}) \cdot\left(\frac{3}{2} \cdot\left(\frac{\mathrm{d}_{\mathrm{i}}}{\mathrm{L}_{\mathrm{s}_{\mathrm{i}}}}\right)^{3 / 2}+7 \cdot\left(\frac{\mathrm{d}_{\mathrm{i}}}{\mathrm{L}_{\mathrm{s}_{\mathrm{i}}}}\right)^{3}\right)\right]
$$

The total vehicle resistance is hence expressed as follows:

$$
\mathrm{R}_{\mathrm{s}}=\frac{1}{2} \rho \cdot \mathrm{v}^{2} \cdot \sum_{\mathrm{i}=1}^{\mathrm{n}}\left\{\mathrm{C}_{\mathrm{v}_{\mathrm{i},}, \mathrm{s}}(\overline{\mathrm{x}}) \cdot \Omega_{\mathrm{i}}(\overline{\mathrm{x}}) \cdot\left[1+\frac{3}{2} \cdot\left(\frac{\mathrm{d}_{\mathrm{i}}}{\mathrm{L}_{\mathrm{s}_{\mathrm{i}}}}\right)^{3 / 2}+7 \cdot\left(\frac{\mathrm{d}_{\mathrm{i}}}{\mathrm{L}_{\mathrm{s}_{\mathrm{i}}}}\right)^{3}\right]\right\}=\alpha_{\mathrm{s}}(\overline{\mathrm{x}}) \cdot \mathrm{v}^{2}
$$

The resistance coefficient $\alpha_{\mathrm{s}}$ takes value respectively $\alpha_{\mathrm{x}}$ or $\alpha_{\mathrm{z}}$ depending on vehicle geometrical parameters and a considered direction of its motion.

\section{SPEED-DEPENDENT CHARACTERISTICS OF VEHICLE DISPLACEMENTS TIME}

Under the presented simplifying assumptions, rectilinear motion along s-axis, of a vehicle which moves with a speed corresponding with moderate values of Reynolds number, is described by the non-linear ordinary differential equation of constant coefficients: 


$$
\left(M_{o}(\bar{x})+\Delta M_{s}(\bar{x})\right) \frac{d s^{2}}{d t^{2}}+\alpha_{s}(\bar{x}) \cdot\left(\frac{d s}{d t}\right)^{2}+W(\bar{x})=T_{o}(\bar{x}) \cdot\left(1-\frac{\frac{d s}{d t}}{v_{k}}\right)+P(\bar{x})
$$

On simplification of the description with the use of the following substitutions:

$$
\lambda=\frac{\mathrm{P}-\mathrm{W}+\mathrm{T}_{\mathrm{o}}}{\mathrm{T}_{\mathrm{o}}} ; \mathrm{M}_{\mathrm{s}}=\mathrm{M}_{\mathrm{o}}+\Delta \mathrm{M}_{\mathrm{s}}
$$

$$
M_{s}(\bar{x}) \cdot \frac{d^{2} s}{{d t^{2}}^{2}}=M_{s}(\bar{x}) \cdot \frac{d}{d t}\left(\frac{d s}{d t}\right)=T_{o}(\bar{x}) \cdot\left(\lambda(\bar{x})-\frac{\frac{d s}{d t}}{v_{k}}\right)-\alpha_{s}(\bar{x}) \cdot\left(\frac{d s}{d t}\right)^{2}
$$

which can be transformed to the form of the equation of separated variables:

$$
M_{s} \frac{d\left(\frac{d s}{d t}\right)}{T_{o} \cdot\left(\lambda_{s}-\frac{\frac{d s}{d t}}{v_{k}}\right)-\alpha_{s} \cdot\left(\frac{d s}{d t}\right)^{2}}=d t
$$

The equation can be expressed in the form convenient to integration:

$$
M_{s} \frac{d\left(\frac{d s}{d t}\right)}{\lambda_{s} \cdot T_{o}-2 \frac{T_{o}}{2 v_{k}} \frac{d s}{d t}-\alpha_{s} \cdot\left(\frac{d s}{d t}\right)^{2}}=d t
$$

By denoting as follows:

$$
p(\bar{x})=\frac{T_{o}(\bar{x})}{2 \cdot v_{k}(\bar{x})}
$$

the general integral of the equation can be expressed by the function:

$$
\frac{\mathrm{M}_{\mathrm{s}}}{2 \cdot \sqrt{\mathrm{p}^{2}+\alpha_{\mathrm{s}} \cdot \lambda_{\mathrm{s}} \cdot \mathrm{T}_{\mathrm{o}}}} \ln \left|\frac{\alpha_{\mathrm{s}} \cdot \frac{\mathrm{ds}}{\mathrm{dt}}+\mathrm{p}+\sqrt{\mathrm{p}^{2}+\alpha_{\mathrm{s}} \cdot \lambda_{\mathrm{s}} \cdot \mathrm{T}_{\mathrm{o}}}}{\alpha_{\mathrm{s}} \cdot \frac{\mathrm{ds}}{\mathrm{dt}}+\mathrm{p}-\sqrt{\mathrm{p}^{2}+\alpha_{\mathrm{s}} \cdot \lambda_{\mathrm{s}} \cdot \mathrm{T}_{\mathrm{o}}}}\right|=\mathrm{t}+\mathrm{t}_{\mathrm{o}}
$$

Under the initial condition: if $\mathrm{t}=0$ then

$$
\begin{gathered}
\frac{\mathrm{ds}}{\mathrm{dt}}=\mathrm{v}_{\mathrm{o}} \quad 0 \leq \mathrm{v}_{\mathrm{o}} \leq \mathrm{v}_{\mathrm{k}} \\
\text { and on substitution: } \\
\sqrt{\mathrm{p}^{2}+\alpha_{\mathrm{s}} \cdot \lambda_{\mathrm{s}} \cdot \mathrm{T}_{\mathrm{o}}}=\beta_{\mathrm{s}}(\overline{\mathrm{x}})
\end{gathered}
$$

the particular solution of the equation takes the form of the function $t=f(v, \bar{x})$ :

$$
\mathrm{t}(\mathrm{v}, \overline{\mathrm{x}})=\frac{\mathrm{M}_{\mathrm{s}}}{2 \cdot \beta_{\mathrm{s}}} \cdot \ln \left|\frac{\left(\alpha_{\mathrm{s}} \cdot \mathrm{v}+\mathrm{p}+\beta_{\mathrm{s}}\right) \cdot\left(\alpha_{\mathrm{s}} \cdot \mathrm{v}_{\mathrm{o}}+\mathrm{p}-\beta_{\mathrm{s}}\right)}{\left(\alpha_{\mathrm{s}} \cdot \mathrm{v}+\mathrm{p}-\beta_{\mathrm{s}}\right) \cdot\left(\alpha_{\mathrm{s}} \cdot \mathrm{v}_{\mathrm{o}}+\mathrm{p}+\beta_{\mathrm{s}}\right)}\right|
$$

which represents characteristics of the time $t$ duration after which the vehicle reaches an assumed value of the speed $v$, counting from the instant when vehicle speed has been equal to $v_{0}$.

Time-dependent characteristics of speed and acceleration constitutes the dependence of the vehicle speed $v$ on duration time of its motion, expressed by the function $v=f(t, \bar{x})$ :

$$
\mathrm{v}(\mathrm{t}, \overline{\mathrm{x}})=\frac{\left(\mathrm{p}+\beta_{\mathrm{s}}\right) \cdot\left(\alpha_{\mathrm{s}} \cdot \mathrm{v}_{\mathrm{o}}+\mathrm{p}-\beta_{\mathrm{s}}\right)-\left(\mathrm{p}-\beta_{\mathrm{s}}\right) \cdot\left(\alpha_{\mathrm{s}} \cdot \mathrm{v}_{\mathrm{o}}+\mathrm{p}+\beta_{\mathrm{s}}\right) \cdot \exp \left(\frac{2 \cdot \beta_{\mathrm{s}} \cdot \mathrm{t}}{\mathrm{M}_{\mathrm{s}}}\right)}{\alpha_{\mathrm{s}} \cdot\left[\left(\alpha_{\mathrm{s}} \cdot \mathrm{v}_{\mathrm{o}}+\mathrm{p}+\beta_{\mathrm{s}}\right) \cdot \exp \left(\frac{2 \cdot \beta_{\mathrm{s}} \cdot \mathrm{t}}{\mathrm{M}_{\mathrm{s}}}\right)-\left(\alpha_{\mathrm{s}} \cdot \mathrm{v}_{\mathrm{o}}+\mathrm{p}-\beta_{\mathrm{s}}\right)\right]}
$$

Characteristics of the vehicle acceleration $a(t, \bar{x})$ is expressed by the derivative with respect to time, $v(t, \bar{x})$ : 


$$
a(t, \bar{x})=\frac{\frac{2 \alpha_{s} \cdot \beta_{s}}{M_{s}} \cdot\left(\alpha_{s} \cdot v_{o}+p+\beta_{s}\right) \cdot\left(p-\beta_{s}\right) \cdot\left(\alpha_{s} \cdot v_{o}+p-\beta_{s}\right) \cdot \exp \left(\frac{2 \cdot \beta_{s} \cdot t}{M_{s}}\right)}{\left[\left(p-\beta_{s}\right) \cdot\left(\alpha_{s} \cdot v_{o}+p+\beta_{s}\right) \cdot \exp \left(\frac{2 \cdot \beta_{s} \cdot t}{M_{s}}\right)-\left(\alpha_{s} \cdot v_{o}+p-\beta_{s}\right) \cdot\left(p+\beta_{s}\right)\right]^{2}}
$$

\section{SPEED-DEPENDENT CHARACTERISTICS OF DISPLACEMENTS}

The equation can be transformed to the form:

$$
\frac{\mathrm{M}_{\mathrm{s}} \cdot \mathrm{vdv}}{\lambda_{\mathrm{s}} \cdot \mathrm{T}_{\mathrm{o}}-2 \cdot \mathrm{p} \cdot \mathrm{v}-\alpha_{\mathrm{s}} \cdot \mathrm{v}^{2}}=\mathrm{ds}
$$

and next, by integrating both its sides, the following relation is obtained:

$$
\int \frac{\mathrm{M}_{\mathrm{s}} \cdot \mathrm{vdv}}{\lambda_{\mathrm{s}} \cdot \mathrm{T}_{\mathrm{o}}-2 \cdot \mathrm{p} \cdot \mathrm{v}-\alpha_{\mathrm{s}} \cdot \mathrm{v}^{2}}=\mathrm{s}(\mathrm{v}, \overline{\mathrm{x}})+\mathrm{s}_{\mathrm{o}}
$$

The general solution of the equation is the function $s=f(v, \bar{x})$ :

$$
\frac{\mathrm{M}_{\mathrm{s}}}{2 \cdot \alpha_{\mathrm{s}}} \cdot \ln \left|\lambda_{\mathrm{s}} \cdot \mathrm{T}_{\mathrm{o}}-2 \cdot \mathrm{p} \cdot \mathrm{v}-\alpha_{\mathrm{s}} \cdot \mathrm{v}^{2}\right|+\frac{\mathrm{M}_{\mathrm{s}} \cdot \mathrm{p}}{\alpha_{\mathrm{s}} \cdot \beta_{\mathrm{s}}} \cdot \ln \left|\frac{\alpha_{\mathrm{s}} \cdot \mathrm{v}+\mathrm{p}-\beta_{\mathrm{s}}}{\alpha_{\mathrm{s}} \cdot \mathrm{v}+\mathrm{p}+\beta_{\mathrm{s}}}\right|=\mathrm{s}(\mathrm{v}, \overline{\mathrm{x}})+\mathrm{s}_{\mathrm{o}}
$$

Under the initial condition: if $\mathrm{s}=0$ then $\mathrm{v}=\mathrm{v}_{\mathrm{o}}$, the particular solution takes the form of the characteristics $\mathrm{s}=\mathrm{f}(\mathrm{v}, \overline{\mathrm{x}})$ :

$$
s(v, \bar{x})=\frac{M_{s}}{2 \cdot \alpha_{s}} \cdot \ln \left|\frac{\lambda_{s} \cdot T_{o}-2 \cdot p \cdot v_{o}-\alpha_{s} \cdot v_{o}^{2}}{\lambda_{s} \cdot T_{o}-2 \cdot p \cdot v-\alpha_{s} \cdot v^{2}}\right|+\frac{M_{s} \cdot p}{2 \cdot \alpha_{s} \cdot \beta_{s}} \cdot \ln \left|\frac{\left(\alpha_{s} \cdot v_{o}+p+\beta_{s}\right) \cdot\left(\alpha_{s} \cdot v+p-\beta_{s}\right)}{\left(\alpha_{s} \cdot v_{o}+p-\beta_{s}\right) \cdot\left(\alpha_{s} \cdot v+p+\beta_{s}\right)}\right|
$$

which expresses the relation of the distance (path) covered by the vehicle beginning from the instant when its speed has been equal to $\mathrm{v}_{\mathrm{o}}$ till the instant when it reaches the speed $\mathrm{v}=\mathrm{v}_{\mathrm{o}}=\Delta \mathrm{v}$.

\section{TIME-DEPENDENT CHARACTERISTICS OF DISPLACEMENTS}

By making use of the equation the distance (path) covered during the time $t$ can be expressed by the relation $s=f(t, \bar{x})$ :

$$
\mathrm{s}(\mathrm{t}, \overline{\mathrm{x}})=\int \frac{\left(\mathrm{p}+\beta_{\mathrm{s}}\right) \cdot\left(\alpha_{\mathrm{s}} \cdot \mathrm{v}_{\mathrm{o}}+\mathrm{p}-\beta_{\mathrm{s}}\right)-\left(\mathrm{p}-\beta_{\mathrm{s}}\right) \cdot\left(\alpha_{\mathrm{s}} \cdot \mathrm{v}_{\mathrm{o}}+\mathrm{p}+\beta_{\mathrm{s}}\right) \cdot \exp \left(\frac{2 \cdot \beta_{\mathrm{s}} \cdot \mathrm{t}}{\mathrm{M}_{\mathrm{s}}}\right)}{\alpha_{\mathrm{s}} \cdot\left[\left(\alpha_{\mathrm{s}} \cdot \mathrm{v}_{\mathrm{o}}+\mathrm{p}+\beta_{\mathrm{s}}\right) \cdot \exp \left(\frac{2 \cdot \beta_{\mathrm{s}} \cdot \mathrm{t}}{\mathrm{M}_{\mathrm{s}}}\right)-\left(\alpha_{\mathrm{s}} \cdot \mathrm{v}_{\mathrm{o}}+\mathrm{p}-\beta_{\mathrm{s}}\right)\right]} \mathrm{dt}+\mathrm{s}_{\mathrm{o}}
$$

On transformation of the equation to the form convenient to integration:

$$
\begin{aligned}
& \mathrm{s}(\mathrm{t}, \overline{\mathrm{x}})=\frac{1}{\alpha_{\mathrm{s}}} \int \frac{\left(\mathrm{p}+\beta_{\mathrm{s}}\right) \cdot\left(\alpha_{\mathrm{s}} \cdot \mathrm{v}_{\mathrm{o}}+\mathrm{p}-\beta_{\mathrm{s}}\right) \mathrm{dt}}{\left(\alpha_{\mathrm{s}} \cdot \mathrm{v}_{\mathrm{o}}+\mathrm{p}+\beta_{\mathrm{s}}\right) \cdot \exp \left(\frac{2 \cdot \beta_{\mathrm{s}} \cdot \mathrm{t}}{\mathrm{M}_{\mathrm{s}}}\right)-\left(\alpha_{\mathrm{s}} \cdot \mathrm{v}_{\mathrm{o}}+\mathrm{p}-\beta_{\mathrm{s}}\right)}+ \\
& -\frac{1}{\alpha_{\mathrm{s}}} \int \frac{\left(\mathrm{p}-\beta_{\mathrm{s}}\right) \cdot\left(\alpha_{\mathrm{s}} \cdot \mathrm{v}_{\mathrm{o}}+\mathrm{p}+\beta_{\mathrm{s}}\right) \cdot \exp \left(\frac{2 \cdot \beta_{\mathrm{s}} \cdot \mathrm{t}}{\mathrm{M}_{\mathrm{s}}}\right) \mathrm{dt}}{\left(\alpha_{\mathrm{s}} \cdot \mathrm{v}_{\mathrm{o}}+\mathrm{p}+\beta_{\mathrm{s}}\right) \cdot \exp \left(\frac{2 \cdot \beta_{\mathrm{s}} \cdot \mathrm{t}}{\mathrm{M}_{\mathrm{s}}}\right)-\left(\alpha_{\mathrm{s}} \cdot \mathrm{v}_{\mathrm{o}}+\mathrm{p}-\beta_{\mathrm{s}}\right)} \mathrm{dt}+\mathrm{s}_{\mathrm{o}}
\end{aligned}
$$

the general solution of the equation is obtained in the form of the function $\mathrm{s}=\mathrm{f}(\mathrm{t}, \overline{\mathrm{x}})$ :

$$
\mathrm{s}(\mathrm{t}, \overline{\mathrm{x}})=\frac{\mathrm{M}_{\mathrm{s}}}{\alpha_{\mathrm{s}}} \ln \left|\left(\alpha_{\mathrm{s}} \cdot \mathrm{v}_{\mathrm{o}}+\mathrm{p}+\beta_{\mathrm{s}}\right) \cdot \exp \left(\frac{2 \cdot \beta_{\mathrm{s}} \cdot \mathrm{t}}{\mathrm{M}_{\mathrm{s}}}\right)-\left(\alpha_{\mathrm{s}} \cdot \mathrm{v}_{\mathrm{o}}+\mathrm{p}-\beta_{\mathrm{s}}\right)\right|-\frac{\left(\mathrm{p}+\beta_{\mathrm{s}}\right) \cdot \mathrm{t}}{\mathrm{M}_{\mathrm{s}}}+\mathrm{s}_{\mathrm{o}}
$$


By imposing the initial condition: if $\mathrm{t}=\mathrm{t}_{\mathrm{o}}$ then $\mathrm{s}=0$, the searched particular solution achieves the form of the function:

$$
\left.\mathrm{s}(\mathrm{t}, \overline{\mathrm{x}})=\frac{\mathrm{M}_{\mathrm{s}}}{\alpha_{\mathrm{s}}} \cdot \ln \left|\frac{\left(\alpha_{\mathrm{s}} \cdot \mathrm{v}_{\mathrm{o}}+\mathrm{p}+\beta_{\mathrm{s}}\right) \cdot \exp \left(\frac{2 \cdot \beta_{\mathrm{s}} \cdot \mathrm{t}}{\mathrm{M}_{\mathrm{s}}}\right)-\left(\alpha_{\mathrm{s}} \cdot \mathrm{v}_{\mathrm{o}}+\mathrm{p}-\beta_{\mathrm{s}}\right)}{\left(\alpha_{\mathrm{s}} \cdot \mathrm{v}_{\mathrm{o}}+\mathrm{p}+\beta_{\mathrm{s}}\right) \cdot \exp \left(\frac{2 \cdot \beta_{\mathrm{s}} \cdot \mathrm{t}_{\mathrm{o}}}{\mathrm{M}_{\mathrm{s}}}\right)-\left(\alpha_{\mathrm{s}} \cdot \mathrm{v}_{\mathrm{o}}+\mathrm{p}-\beta_{\mathrm{s}}\right)}\right|-\frac{\left(\mathrm{p}+\beta_{\mathrm{s}}\right) \cdot\left(\mathrm{t}-\mathrm{t}_{\mathrm{o}}\right)}{\mathrm{M}_{\mathrm{s}}}\right]
$$

The parameter $\mathrm{v}_{\mathrm{o}}$ which appears in the formulas, determines the vehicle speed in the instant $\mathrm{t}_{\mathrm{o}}$.

The presented relationships express characteristics useful in the designing

of vehicle geometrical configuration and the determining of propulsion system parameters.

\section{EXAMPLES OF APPLICATION OF THE METHOD}

\section{Vehicle geometrical configuration}

A vehicle of geometrical configuration composed of $\mathrm{i}=0,1,2,3 \ldots$ spatial frame rods; $j=0,1,2,3 \ldots$ axially symmetrical slender pontoons; $\mathrm{k}=0,1,2,3 \ldots$ equipment elements in the form of plates, discs or cylinders is considered. The vehicle is moved by $\mathrm{p}=0,1,2,3 \ldots$ screw propellers, as shown in Fig. 2.

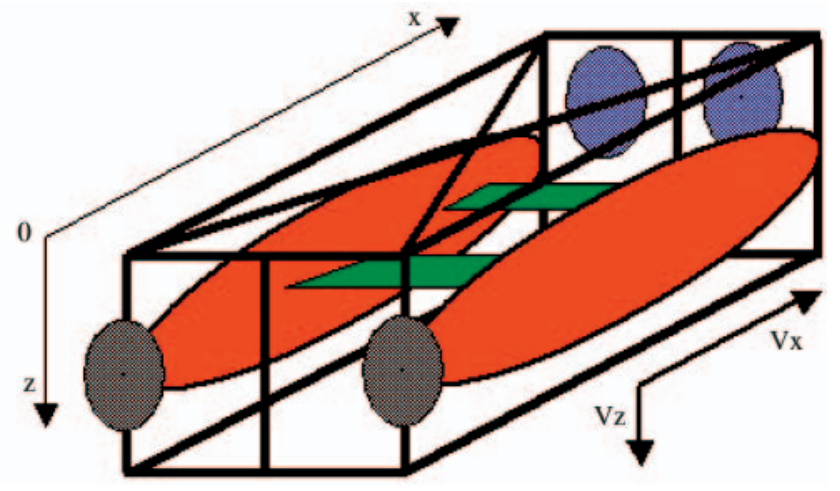

Fig. 2. Draft configuration of the example vehicle „, Scylla”

The vehicle „Scylla” is under consideration, its data used to perform example calculations are listed in Tab. 1.

In the example the components of the vector $\bar{x}$ concerning the screw propeller parameters relate to the B.5.60 propeller type: $\mathrm{H} / \mathrm{D}_{\mathrm{p}}=0.5, \mathrm{~K}_{\mathrm{T}}(\mathrm{J}=0)=0.25, \mathrm{~K}_{\mathrm{O}}(\mathrm{J}=0)=0.025$, $\mathrm{J}_{\mathrm{k}}(\mathrm{T}=0)=0.55, \mathrm{v}_{\mathrm{k}}=\mathrm{J}_{\mathrm{k}} \cdot \mathrm{n}_{\mathrm{p}} \cdot \mathrm{D}_{\mathrm{p}}$, where $\mathrm{J}_{\mathrm{k}}$ is the propeller zerothrust advance ratio. For calculations of motion along $\mathrm{x}$-axis the approximate value $\xi_{x} \approx 0.25$ was assumed, and in the case of motion along z-axis - the value $\xi_{\mathrm{z}} \approx 0.5$.

\section{Simulation of horizontal motion of the vehicle}

The problem of determination of kinematic and dynamic motion characteristics of a vehicle having set geometrical configuration and determined propulsion parameters is considered for the case of motion along $\mathrm{x}$-axis. The horizontal motion of the "Scylla" vehicle of the mass displacement $\mathrm{D}=1.6 \mathrm{t}$ is produced by thrust of two screw propellers of $0.35 \mathrm{~m}$ diameter. The resulting kinematic and dynamic motion characteristics are graphically presented in Fig. 3 .

From the obtained results it follows that at the starting-up power of $1 \mathrm{~kW}$ delivered to each of the propellers, the vehicle develops the constant speed of $\sim 0.85 \mathrm{~m} / \mathrm{s}$ after passing the time of $8 \mathrm{~s}$ and covering the distance of $6 \mathrm{~m}$ by the vehicle. At this constant speed each of the propellers consumes the power of $0.8 \mathrm{~kW}$ at the rotational speed of $600 \mathrm{rpm}$.
Tab. 1. Basic design parameters (i.e. components of the vector $\bar{x}$ ) of the vehicle ,Scylla”

\begin{tabular}{|c|c|c|c|}
\hline \multicolumn{4}{|c|}{ Pontoon geometrical description } \\
\hline \multicolumn{4}{|c|}{ Attribute - spheroids } \\
\hline $\mathrm{Np}$ & 2 & {$[-]$} & Number \\
\hline $\mathrm{Lp}$ & 5.00 & {$[\mathrm{~m}]$} & Length \\
\hline $\mathrm{Dp}$ & 0.50 & {$[\mathrm{~m}]$} & Diameter \\
\hline $\mathrm{Vp}$ & 0.65 & {$\left[\mathrm{~m}^{3}\right]$} & Volume \\
\hline $\mathrm{Sp}$ & 5.58 & {$\left[\mathrm{~m}^{2}\right]$} & Wetted Area \\
\hline \multicolumn{4}{|c|}{ Geometrical description of frame longitudinal elements } \\
\hline \multicolumn{4}{|c|}{ Attribute - cylinders } \\
\hline $\mathrm{Nw}$ & 6 & {$[-]$} & Number \\
\hline $\mathrm{Lw}$ & 5.00 & [m] & Length \\
\hline Dw & 0.10 & {$[\mathrm{~m}]$} & Diameter \\
\hline $\mathrm{Vw}$ & 0.04 & {$\left[\mathrm{~m}^{3}\right]$} & Volume \\
\hline $\mathrm{Sw}$ & 1.57 & {$\left[\mathrm{~m}^{2}\right]$} & Wetted Area \\
\hline \multicolumn{4}{|c|}{ Geometrical description of frame transverse elements } \\
\hline \multicolumn{4}{|c|}{ Attribute - cylinders } \\
\hline Nk & 8 & {$[-]$} & Number \\
\hline Lk & 1.50 & {$[\mathrm{~m}]$} & Length \\
\hline $\mathrm{Dk}$ & 0.05 & {$[\mathrm{~m}]$} & Diameter \\
\hline $\mathrm{Vk}$ & 0.01 & {$\left[\mathrm{~m}^{3}\right]$} & Volume \\
\hline Sk & 0.24 & {$\left[\mathrm{~m}^{2}\right]$} & Wetted Area \\
\hline \multicolumn{4}{|c|}{ Geometrical description of outside equipment } \\
\hline \multicolumn{4}{|c|}{ Attribute - plates\&discs } \\
\hline $\mathrm{Nt}$ & 2 & {$[-]$} & Number \\
\hline $\mathrm{Lt}$ & 0.15 & {$[\mathrm{~m}]$} & Length \\
\hline $\mathrm{Dt}$ & 0.30 & [m] & Diameter \\
\hline $\mathrm{Vt}$ & 0.01 & {$\left[\mathrm{~m}^{3}\right]$} & Volume \\
\hline $\mathrm{St}$ & 0.42 & {$\left[\mathrm{~m}^{2}\right]$} & Wetted Area \\
\hline \multicolumn{4}{|c|}{ Parameters of screw propeller of the type B.5.60. H/D $=0.5$} \\
\hline Nps & 2 & {$[-]$} & Number \\
\hline Ds & 0.35 & {$[\mathrm{~m}]$} & Diameter \\
\hline Ns & var & [rpm] & Rotational speed \\
\hline
\end{tabular}

In the case of delivering the starting-up power of $2 \mathrm{~kW}$ to each of the propellers their rotational speed increases from 600 $\mathrm{rpm}$ to $750 \mathrm{rpm}$, and the vehicle speed increases to $1 \mathrm{~m} / \mathrm{s}$. After steadying the speed, each of the propellers will consume the power of $1.6 \mathrm{~kW}$. The remaining characteristics are presented in Fig. 4. 
"Scylla" Underwater Vehicle Kinematic\& Dynamic Characteristics

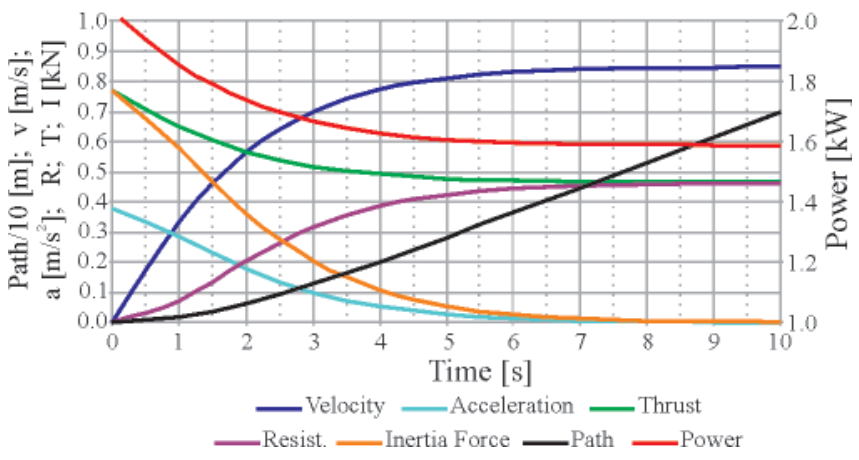

Fig. 3. Horizontal motion characteristics of the vehicle "Scylla” at the propulsion power of $2 \times 1 \mathrm{~kW}$

"Scylla" Underwater Vehicle Kinematic\& Dynamic Characteristics

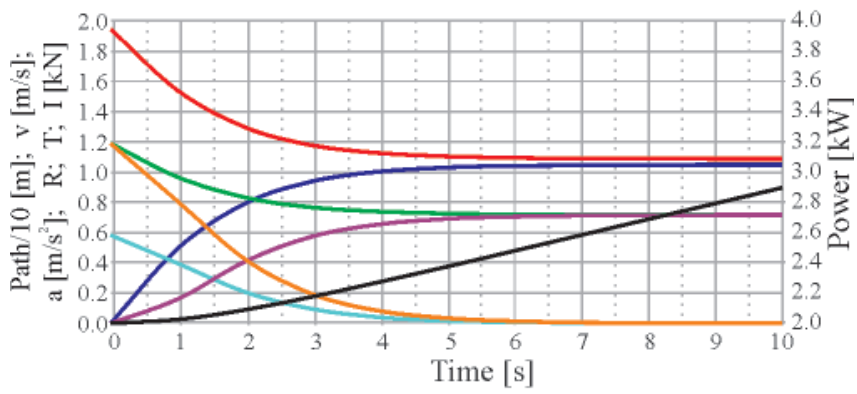

- Velocity —Acceleration —-Thrust

Fig. 4. Horizontal motion characteristics of the vehicle,, Scylla" at the propulsion power of $2 \times 2 \mathrm{~kW}$

\section{Simulation of vertical motion of the vehicle}

In the case of the motion along $\mathrm{z}$-axis the problem of determination of kinematic and dynamic motion characteristics is considered for the vehicle of set geometrical configuration and buoyancy/weight ratio controlled by chosen mass of water ballast. Vertical motion of the vehicle is produced by difference between buoyancy and weight forces of the vehicle without any interference of screw propulsion.

The resulting kinematic and dynamic motion characteristics are graphically presented in Fig. 5. for the case of the surplus of weight over buoyancy, equal to $\mathrm{P}-\mathrm{W}=0.981 \mathrm{kN}$, which resulted from taking the water ballast of $0.1 \mathrm{t}$ mass.

"Scylla" Underwater Vehicle

Kinematic\& Dynamic Characteristics

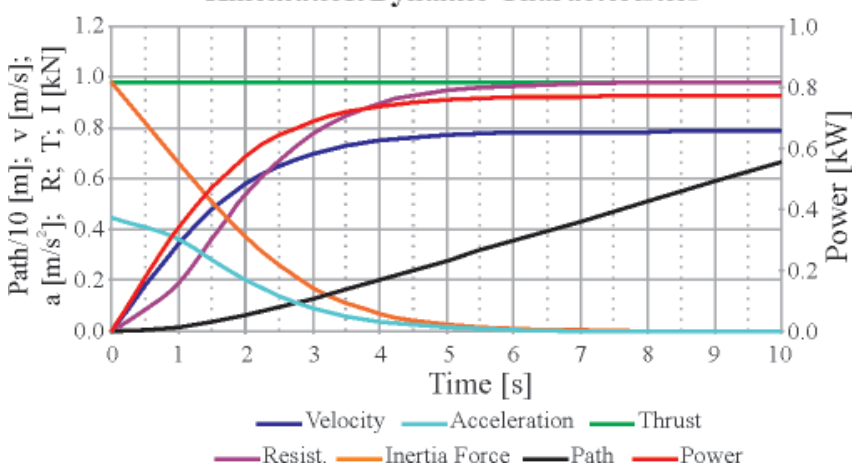

Fig. 5. Vertical motion characteristics of the vehicle,, Scylla”, resulting from taking the water ballast of 0.1 t mass

In this case the propulsion power is determined by the product of vehicle's speed and difference of its weight and buoyancy.

\section{CONCLUSIONS}

The presented method is characteristic of simplicity of application and prediction merits, that makes it useful in aiding and performing the preliminary design tasks.

The method can serve both for computer aided design of underwater vehicles and realization of parametric investigations aimed at determination of relations (e.g. indices) useful in formulating the preliminary design methods for underwater vehicles.

O Parametric structure of the method makes changes in design decisions easier due to simple way of introducing appropriate corrections in order to achieve design solutions of expected operational and technical features of designed vehicle.

To validate of the method and implement it to engineering design practice, verification and calibration of the coefficients of motion equations by means of experimental tests is required in order to determine their values correlated with various vehicle form configurations.

The method can be refined by adding available propulsion characteristics (e.g. of ducted propellers) as well as those of vehicle resistance. In particular, the method can be improved by taking into account the phenomena described in [7] as well as influence of high pressure on resistance and propulsion phenomena.

O An initial comparison of the obtained results with the data available from the subject-matter literature, e.g. [1] (comparison of delivered power and predicted vehicle speed values) indicates that the vehicle motion characteristics determined by using the presented method are realistic.

\section{NOMENCLATURE}

$\mathrm{k}_{\mathrm{s}} \quad$ - form coefficient for motion in s-direction

$\mathrm{m}-$ number of propellers

$n_{p} \quad-$ rotational speed of screw propellers

$\mathrm{v}-$ vehicle speed $\left(\mathrm{v}<\mathrm{v}_{\mathrm{k}}\right)$

$\mathrm{v} \quad$ - initial speed of vehicle

$\mathrm{v}_{\mathrm{k}}-$ propeller zero-thrust speed

w - wake factor

$\mathrm{B}$ - water mass acceleration force

$\mathrm{C}_{\mathrm{f}}$ - friction resistance coefficient for motion in s-direction

$\mathrm{D}^{\mathrm{i}, \mathrm{s}}$ - vehicle buoyancy

$\mathrm{D}_{\mathrm{p}}$ - propeller diameter

$\mathrm{J}_{\mathrm{k}}^{\mathrm{p}}$ - propeller zero-thrust advance ratio

$\mathrm{K}_{\mathrm{T}}$ - propeller bollard thrust coefficient

$\mathrm{K}_{\mathrm{O}}$ - propeller bollard torque coefficient

$\mathrm{M}_{\mathrm{b}}$ - water ballast mass

$\mathrm{M}_{\mathrm{j}}$ - components of mass of vehicle

$\mathrm{M}_{\mathrm{o}}$ - mass of vehicle with water ballast

$M_{p}$ - mass of vehicle without water ballast

$\mathrm{M}^{\mathrm{p}}$ - accelerated mass

$\mathrm{P}^{\mathrm{s}}$ - vehicle weight

$\mathrm{R}_{\mathrm{tx}}$ - vehicle resistance to motion along $\mathrm{x}$-axis

$\mathrm{R}_{\mathrm{tz}}$ - vehicle resistance to motion along $\mathrm{x}$-axis

$\mathrm{T}_{\mathrm{o}}^{\mathrm{tz}}-$ propeller bollard thrust

$\mathrm{T}_{\mathrm{N}}^{\mathrm{o}}-$ thrust of propellers

$\mathrm{V}$ - vehicle volumetric displacement

W - vehicle buoyancy force

$v \quad-$ kinematic viscosity coefficient of water

$\rho \quad-$ density of water

$\xi \quad$ - added water mass coefficient for motion in s-direction

- vector of parameters which describe a vehicle

$\Delta \mathrm{M}_{\mathrm{s}}$ - added water mass

$\Omega_{\mathrm{j}}{ }^{\mathrm{s}}-$ reference surface areas of vehicle elements. 


\section{BIBLIOGRAPHY}

1. http://auvlab.mit.edu/resources/HV-SGT (10.01.2009)

2. Fang M.C., et al.: On the Behavior of an Underwater Remotly Operated Vehicle in a Uniform Current. Marine Technology. Vol. 45, No. 4, 2008

3. Garus J.: Identification of motion parameters of floating objects in operational conditions by using numerical methods (in Polish). Doctor thesis, Polish Naval Academy, Gdynia 1993

4. Żak A.: Identification of dynamic motion of unmanned underwater vehicle in operational conditions (in Polish). Doctor thesis, Polish Naval Academy, Gdynia 2006

5. Hoerner S.F.: Fluid dynamic drag. Published by the Author. 1965

6. Bukowski J.: Fluid Mechanics (in Polish). State Scientific Publishing House (Państwowe Wydawnictwo Naukowe). Warszawa 1976
7. Nikołajew E.P.: A contribution to the problem of acceptance of stationarity hypothesis for assessment of resistance of bodies of bad around-flow (in Polish). 2nd Symposium on Ship Hydromechanics. Application of model tests to ship design. Ship Design and Research Centre, Gdańsk 1974.

\section{CONTACT WITH THE AUTHOR}

Assoc. Prof. Jan P. Michalski

Faculty of Ocean Engineering and Ship Technology

Gdansk University of Technology Narutowicza 11/12

80-952 Gdansk, POLAND e-mail : janmi@pg.gda.pl 